\title{
Dynamics of the gender structure of teaching staff in modern Russia
}

\author{
Lyudmila Alekseevna Brushkova ${ }^{1^{*}}$, Ivan Andreevich Vladimirov² , and Niginakhon \\ Arslanovna Shermukhamedova ${ }^{3}$ \\ ${ }^{1}$ Financial University under the Government of the Russian Federation, Department of Sociology, \\ Moscow, Russia \\ ${ }^{2}$ Financial University under the Government of the Russian Federation, Faculty of Social Sciences \\ and Mass Communications, Moscow, Russia \\ ${ }^{3}$ National University of Uzbekistan named after Mirzo Ulugbek, Department of Philosophy and \\ Fundamentals of Spirituality, Tashkent, Uzbekistan
}

\begin{abstract}
The subject of the article is the dynamics of the gender structure of university staff in modern Russia. The purpose of the article is to reveal the changes that have occurred in the gender structure of university teachers over the past 20 years. Research methods include the analysis of statistical and sociological data, cross-tabulation and calculation of the feminization index. The authors note that over the twenty-year period, the feminization of Russian universities has intensified. It captures increasingly higher levels of the university job hierarchy, which is manifested in an increase in the number of women in the positions of associate professors, professors, heads of departments, vice-rectors, etc. The significant predominance of women in the positions of assistants, teachers and senior teachers is the basis for the further feminization of university staff in Russia. The analysis of the gender structure of postgraduate and doctoral students shows that women lag behind men only in the youngest age categories of postgraduate students (up to 27 years old) and doctoral students (up to 39 years old) and the oldest category of doctoral students (over 60 years old). This is explained by the fact that at these ages, women are likely to perform their reproductive and educational functions. Women dominate in all other age cohorts of postgraduate and doctoral students. The authors conclude that, despite the existing manifestations of discrimination against women in higher education (gender pay gap, low representation of women at the highest level of university administration, the glass ceiling effect in promoting women up the career ladder, etc.) In general, women are making progress in higher education, making the industry increasingly feminized.
\end{abstract}

Keywords: gender, employment, education, universities, feminization, teachers, discrimination, Russian society.

\footnotetext{
* Corresponding author: $\underline{\text { lbrushkova@fa.ru }}$
} 


\section{Introduction}

Today, gender issues are being actively developed by representatives of various sciences, including sociology.

Despite the fact that there is a lot in common in gender issues of different groups of countries, there is also significant specificity due to the level of their economic, political and national-cultural development. Foreign research focuses on studying the issues of positioning men and women in popular culture, including advertising [1, 2]. Special attention is paid to the study of gender issues in the black community [3, 4]. A fairly large number of works are devoted to the problem of women leaders [5], women on the board of directors [6], women in non-traditional female positions [7] and women entrepreneurs [8].

The transitional countries, including Russia, are still under the influence of the socialist legacy, despite the fact that the period of socialism is increasingly receding into the past (this year it has been exactly 30 years since the collapse of the USSR and the socialist system). Thus, in the works of the famous Russian sociologist Sillaste, modern gender processes are considered in the context of the formation of a new gender order that comes from the West and does not always correspond to Russian cultural and national traditions [9].

The basis of the gender order in modern society is the gender structure of employment the distribution of men and women by various spheres and employment levels. It is not only part of the social division of labor, but also one of the manifestations of social inequality within the population. Over the past thirty years, Russia has been going through a complex and painful transformation of all spheres of society, moving onto the "rails" of capitalism. Certainly, this also applies to gender relations in the labor market.

The gender segregation of the Russian labor market and the professional mobility of men and women are well studied in the works by Maltseva and Roshchin [10], the career strategies of men and women in the context of the gender order reproduction are considered in the works by Tartakovskaya [11]. The works by Sillaste are devoted to the gender aspects of poverty [12]. Self-employment in terms of gender is analyzed in the works by Brushkova [13].

The gender structure of employment in any country is characterized by a certain level of segregation of men and women, a manifestation of which is masculinization or feminization of professions and employment spheres. The main negative consequence of gender segregation is the gender pay gap and hence the life opportunities of men and women [14]. In Russia, according to the Federal State Statistics Service (Rosstat), women's average salary in 2019 was $67.3 \%$ of men's salary (in $2015-73 \%$ ), which indicates an increase in the gender pay gap [15].

According to Rosstat data for 2019, female industries in Russia include as follows:

- education ( $82 \%$ of women);

- health care and social services $(80 \%)$;

- hotels and catering facilities (74\%);

- finance and insurance (69\%);

- culture, sports, entertainment and leisure (66\%).

The list of male industries looks completely different:

- construction ( $87 \%$ of men);

- mining (82\%);

- transportation and storage (78\%);

- water supply, sewerage, waste collection and disposal (67\%);

- information and communication (65\%). 
The sphere of higher education and its transformation is the object of close attention of Russian sociologists. Thus, the age peculiarities of the structure of teaching staff in Russia, as well as the features of the dynamics of mass higher education in Russia, were analyzed in the works by Pugach [16].

The purpose of this article is to analyze the dynamics of the gender structure of teaching staff in modern Russia (over the past 20 years), its main trends and mechanisms. The choice of higher education as a subject of analysis is deliberate, since, according to statistics, the permanent process of feminization is recorded in this sphere.

\section{$2 \quad$ Materials and methods}

The latest statistical collection "Women and Men of Russia" prepared by Rosstat was used as the main source of information. Unfortunately, today there is no representative sociological data on the gender structure of teachers in Russian universities. The research mostly concerned only individual universities.

The cross-tabulation method was used in the work for the secondary analysis of official statistical data. To visualize data on age cohorts of postgraduate and doctoral students, the feminization index was calculated for each group.

\section{$3 \quad$ Results}

Russia is one of the few countries in the world where the education sector is characterized by a very high level of feminization. It reaches its maximum values at the level of preschool and school education, where it is often possible to find an almost entirely female composition of working groups.

According to the latest data from Rosstat, the ratio of women and men in professional positions of teachers in preschool institutions is $99 \%$ versus $1 \%$. The share of women among teachers providing training in primary, basic and secondary education programs is also very high $-88 \%[15]$.

Over the past 20 years, there has been a gradual but steady increase in the number of female university teachers. Currently, $58 \%$ of women and $42 \%$ of men work in the country's universities. In 2000 , the ratio was almost parity $-48 \%$ of women versus $52 \%$ of men, and the difference was a little over 10 thousand people [15].

Feminization is taking over increasingly higher levels of the hierarchy of Russian universities. Currently, women dominate not only in the positions of assistants, teachers and senior teachers, but also among associate professors of universities - more than $60 \%$. The number of women among deans and heads of departments is growing -45 and $47 \%$, respectively, as well as among professors $-35 \%$ [15].

By comparison, in 2000, women lagged behind men even at the level of associate professors (only 44\% were women), while at the level of professors, deans and heads of departments women were less than $30 \%$ [15].

Currently, $70-90 \%$ of the positions of assistants, teachers and senior teachers are occupied by women, which is definitely the basis for further feminization of teaching staff of Russian universities.

In Russia, as in most developed and transitional countries, girls steadily dominate the environment of university students. As for postgraduate and doctoral studies, the situation is not so obvious (see Table 1). 
Table 1. Gender structure of students, postgraduates and doctoral students, \% [15].

\begin{tabular}{|l|c|c|}
\hline \multicolumn{1}{|c|}{ Student category } & Women & Men \\
\hline Students in undergraduate, specialist and graduate programs (students) & 53 & 47 \\
\hline $\begin{array}{l}\text { Students in academic and teaching staff training programs (postgraduate } \\
\text { students) }\end{array}$ & 44 & 56 \\
\hline Students in academic staff training programs (doctoral students) & 46 & 54 \\
\hline
\end{tabular}

Among those enrolled in universities the number of girls is $53 \%$, while among postgraduate students in all sciences $-44 \%$ on average, and in engineering and general scientific disciplines - about $25 \%$. This is most likely explained by the fact that after graduation, a certain part of the girls switches to performing reproductive and family functions, which forces them to interrupt their careers for a certain period and postpone the implementation of their scientific and professional plans.

However, as for the gender ratio of postgraduate and doctoral students by age, it can be seen that the lag in the number of women is observed only in the youngest (among postgraduate and doctoral students) and the oldest (among doctoral students) age groups, which, as noted above, is more likely due to their involvement in childbearing, childcare and upbringing of children and grandchildren. But women recover their positions and begin to confidently outpace men at older ages - after the age of 30 among postgraduate students and after the age of 40 among doctoral students. Moreover, the gender gap was established at the level of $10-12 \%$ (see Tables 2 and 3 ).

Table 2. The number of postgraduate students by age group, $\%$ [15].

\begin{tabular}{|l|c|c|}
\hline \multicolumn{1}{|c|}{ Age group } & Women & Men \\
\hline Up to 26 y.o. & 36 & 64 \\
\hline $27-29$ y.o. & 50 & 50 \\
\hline 30 -34 y.o. & 56 & 44 \\
\hline $35-39$ y.o. & 55 & 45 \\
\hline 40 y.o. and older & 56 & 44 \\
\hline
\end{tabular}

Table 3. The number of doctoral students by age group, $\%$ [15].

\begin{tabular}{|l|c|c|}
\hline \multicolumn{1}{|c|}{ Age group } & Women & Men \\
\hline Up to 39 y.o. & 38 & 62 \\
\hline $40-49$ y.o. & 56 & 44 \\
\hline $50-59$ y.o. & 56 & 44 \\
\hline 60 y.o. and older & 24 & 76 \\
\hline
\end{tabular}

To reflect the degree of feminization of different age groups of postgraduate and doctoral students, the authors calculated the feminization indices (Fig. 1 and Fig. 2), where value 1 is gender parity, value greater than 1 is dominance of women, value less than 1 is dominance of men. 


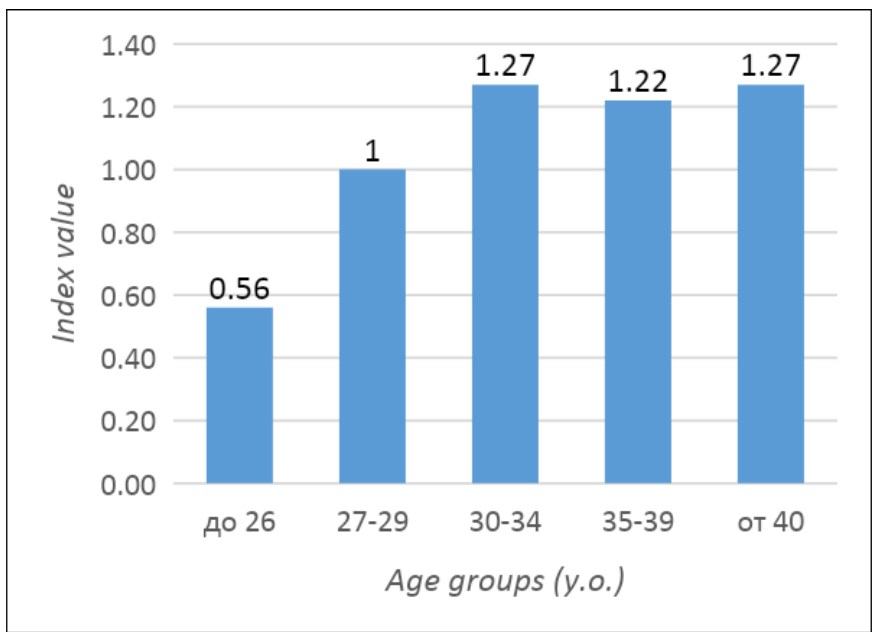

Fig. 1. Postgraduate feminization index. Source: Compiled by the authors.

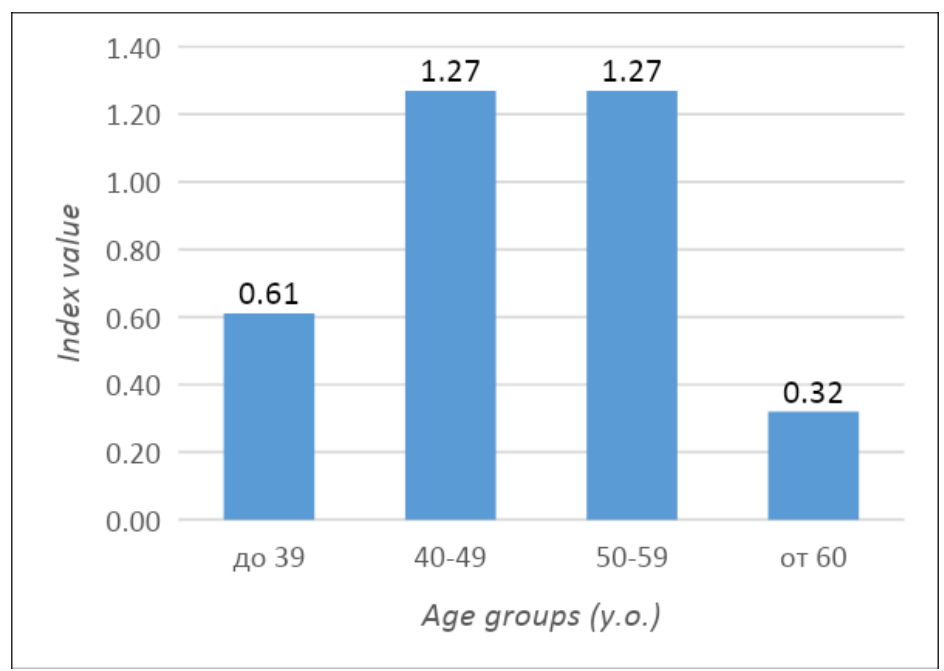

Fig. 2. Doctoral feminization index. Source: Compiled by the authors.

The postgraduate feminization index clearly demonstrates that women confidently dominate among the older age groups of postgraduate students, and only in the 27-29 age groups gender parity is observed.

The doctoral feminization index shows that there is no gender parity in this category of doctoral students. In the groups aged under 39 and over 60, men predominate among doctoral students, while in the middle age group (aged 40-59) there is a noticeable asymmetry in favor of women, which is similar by its values to the situation at the postgraduate level.

According to the international monitoring, despite much housework and childcare, Russian women are more likely than men to obtain doctoral degrees. Thus, in the 2015-2016 academic year, 55\% of all doctors of sciences were women and 45\% - men [17].

Over the past 20 years, the qualitative characteristics of the Russian scientific female community have significantly improved. In 2019, 42\% of researchers with PhD degrees 
were women (an increase of $8 \%$ since 2000 ), doctors of sciences - $27 \%$ (an increase of $8 \%$ ) (see Table 4).

Moreover, since 2015 (among PhDs) and 2018 (among doctors of sciences), these indicators have not increased, which indicates a certain stagnation in this area, the reasons for which need to be specially studied.

Table 4. The number of women with PhD and doctoral degrees, \% [15].

\begin{tabular}{|c|c|c|}
\hline Year & $\mathrm{PhD}$ & Doctor of Science \\
\hline 2000 & 34 & 19 \\
\hline 2005 & 36 & 21 \\
\hline 2010 & 39 & 23 \\
\hline 2015 & 42 & 26 \\
\hline 2016 & 42 & 26 \\
\hline 2017 & 42 & 26 \\
\hline 2018 & 42 & 27 \\
\hline 2019 & 42 & 27 \\
\hline
\end{tabular}

\section{Discussion}

The development of higher education in Russia, including postgraduate and doctoral studies, is explained by some researchers by the market laws of supply and demand for this resource [18]. However, within the framework of this approach, it is impossible to explain the gender disparities that have formed in the structure of academic and teaching staff in Russian universities.

In the authors' opinion, women's increased interest in academic and teaching career can be considered in the context of the human capital theory by Schultz, Becker and the multiple capital theory by Bourdieu.

The authors think that since the 1960s, in industrialized countries, including Russia, women have deliberately begun to develop human (according to Bourdieu, cultural) capital, both their own capital and their daughters' as well. This is evidenced by statistical data on the better school and university performance of girls and young women (in comparison with boys and young men), the numerical dominance of girls in universities, their greater involvement in extracurricular activities, various courses of supplementary education, etc. The authors' study of parents' investments in supplementary education for children, conducted in 2019, also supports this hypothesis.

\section{Conclusion}

The analysis of the gender structure of teaching staff in Russia over the past 20 years allows concluding that this sphere of activity is feminized. Currently, women dominate at all levels of the higher educational hierarchy except for the highest positions (professors, heads of departments, vice-rectors and rectors).

In the future, the feminization of this sphere will only intensify, since already now women prevail in the field of training teaching and academic staff (postgraduate and doctoral studies), as well as in lower teaching positions (assistants, teachers and senior teachers).

This state cannot be considered optimal, since the lag of men in this sphere can cause negative socio-economic and cultural consequences, including long-term ones. It is optimal to maintain gender balance in higher education, when both genders and society as a whole benefit equally. 
The study found alarming tendencies towards stagnation in the proportion of female $\mathrm{PhDs}$ and doctors of science. Finding out the reasons for this requires additional research.

Despite the obvious progress in promoting women in employment in Russian universities, there are still certain "zones" of gender discrimination. Women are still underrepresented in the senior management of universities, as well as in the bodies regulating higher education (ministries, etc.). The predominance of women in lower and middle teaching positions is one of the reasons that women's average salaries in universities are lower than those of men.

The provisions and conclusions of this study can be useful to everyone involved in the management of higher education in Russia. The results obtained can also be used in further research on gender problems in modern society, as well as in the process of teaching sociological and managerial disciplines.

The study was carried out within the framework of the scientific project "Challenges and risks of the formation of a new gender order and the social mechanism of its management in Russia" No. 20-011-00519 with the financial support of the Russian Foundation for Basic Research.

\section{References}

1. S.L. Grau, Y.C. Zotos, Int J Adv, 35(5), $761-770$ (2016). https://doi.org/10.1080/02650487.2016.1203556

2. L.T. Zayer, M.A. McGrath, P. Castro-Gonzalez, Europ J Market, 54(1), 238-260 (2020). https://doi.org/10.1108/EJM-07-2018-0502

3. M. Ong, J.M. Smith, L.T. Ko, J Res Sci Teach, 55(2), 206-245 (2018). https://doi.org/10.1002/tea.21417

4. L. Rosenthal, M. Lobel, Ethn Health, 25(3), 367-392 (2020). https://doi.org/10.1080/13557858.2018.1439896

5. M.H. Elmagrhi, C.G. Ntim, A.A. Elamer, Q. Zhang, Bus Strat Environ, 28(1), 206-220 (2018). https://doi.org/10.1002/bse.2250

6. X. He, S. Jiang, Bus Strat Environ, 28(7), 1341-1356 (2019). https://doi.org/10.1002/bse.2319

7. J. Harris, S.G. Naoum, J. Rizzuto, C. Egbu, J Manag Eng, 36(2) (2020). https://doi.org/10.1061/(ASCE)ME.1943-5479.0000731

8. R.T. Harrison, C.M. Leitch, M. McAdam, J Econ Geog, 20(4), 1041-1067 (2020). https://doi.org/10.1093/JEG/LBZ035

9. G.G. Sillaste, Woman Rus Soc, 2, 3-16 (2019). https://doi.org/10.21064/WinRS.2019.2.1

10. I.O. Maltseva, S.Yu. Roshchin, Gendernaya segregatsiya i mobil'nost' na rossiiskom rynke truda [Gender segregation and mobility in the Russian labor market]. (Higher School of Economics Publishing House, Moscow, 2006)

11. I.N. Tartakovskaya, Soc Res, 5, 84-93 (2015)

12. G.G. Sillaste, Digest Sci Life Fin Univ, 5, 6-9 (2018)

13. L.A. Brushkova, Self-govern 3, 27-30 (2020)

14. C. Collins, L.C. Landivar, L. Ruppanner, W.J. Scarborough, Gender, Work Org, 28(S1), 101-112 (2021). https://doi.org/10.1111/gwao.12506 
15. Rosstat opublikoval sbornik "Zhenshchiny i muzhchiny Rossii" - 2020 [Rosstat has published the collection "Women and men of Russia" - 2020]. Accessed on: October 4, 2021. [Online]. Available: https://rosstat.gov.ru/folder/70843/document/115497

16. V.F. Pugach, Higher Edu Rus, 1, 47-55 (2017)

17. Status and Trends in the Education of Racial and Ethnic Groups. Accessed on: October 4, 2021. [Online]. Available: https://nces.ed.gov/programs/raceindicators/

18. V.F. Pugach, Higher Edu Rus, 29(2), 74-82 (2020). https://doi.org/10.31992/0869-3617-2020-29-2-74-82 